\title{
THE IMPAGT OF NATIONAL CULTURE ON EMPLOYEES' ATTITUDES TOWARD HEAVY WORK INVESTMENT: COMPARATIVE APPROACH ROMANIA US. JAPAN
}

\author{
Ion Popa ${ }^{1 *}$, Simona Cătălina Ștefan ${ }^{2}$, Cătălina Florentina Albu ${ }^{3}$, \\ Ștefan Cătălin Popa ${ }^{4}$ and Cristian Vlad ${ }^{5}$ \\ ${ }^{122) 334)}$ University of Economic Studies, Bucharest, Romania \\ ${ }^{5)}$ University of Economic Studies, Bucharest, \\ Romania and Nagaoka University of Technology, Nagaoka, Japan
}

Please cite this article as:

Popa, I., Ștefan, S.C., Albu, C.F., Popa, Ș.C. and Vlad, C., 2020. The Impact of National Culture on Employees' Attitudes Toward Heavy Work Investment: Comparative Approach Romania vs. Japan. Amfiteatru Economic, 22(Special Issue No. 14), pp. 1014-1029

\section{Article History}

Received: 29 June 2020

Revised: 7 August 2020

Accepted: 9 September 2020

DOI: $10.24818 / \mathrm{EA} / 2020 / \mathrm{S} 14 / 1014$

\begin{abstract}
This paper aims to study the heavy work investment's association with different forms of motivation, as well as the positive or negative effects of this investment on a personal and professional level, in the context of two very different national cultures: Romania and Japan. A questionnaire-based survey involving 822 employees in both Romania and Japan was carried out for data collection. The main results, obtained through structural equation modeling, suggest that intrinsic motivation could lead Romanian and Japanese employees to increase their investment of time and effort in work. On the other hand, the intensity of work will be positively reflected in their job satisfaction and professional performance and will lead to reduction in work-family conflict and turnover intention, while the massive investment of time will have opposite consequences. All these relationships are statistically different for employees in Romania and Japan, thus supporting the moderating effect of national culture. These results could be useful to both employees and managers in Romania and Japan to decide on the time and effort should be invested in work, considering both their positive and negative effects for employee and organization.
\end{abstract}

Keywords: heavy work investment, motivation, culture, job satisfaction, work performance, Romania, Japan.

JEL Classification: D83, I23, J01, J23, J24, J28

* Corresponding author, Ion Popa - e-mail: ion.popa@man.ase.ro 


\section{Introduction}

The current economy is influenced by various phenomena which have the effect of rapidly changing strategic organizational workings and operational initiatives. These changes are significant for employees and they often translate into works and organizational modifications, in terms of intensity, complexity and even the nature of the tasks to be performed. As a result, employees need to invest significant resources for increased performance and efficiency. Researchers (Snir and Harpaz, 2012) have analyzed this type of employee investment and categorized it under the name as "Heavy Work Investment" (HWI). Investors in heavy work are considered to be those employees who spend a considerable amount of time, but also the physical and mental energy in their work (Houlfort, et al., 2014).

As different countries display different cultural values, norms and behaviors, which, in turn, can affect their work values, norms and behaviors (e.g., the Japanese believe that effort and investment in work can bring prosperity, health, and happiness) (Shkoler and Kimura, 2020), HWI is perceived differently, depending on the cultural characteristic of each nation. On the other hand, organizations need to identify how each employee invests in their work and adapt their engagement and motivation system accordingly. Organizational support (OS) is associated with HWI (Schaufeli, 2016) and it is expected to turn employee labor investment into positive results. Therefore, although the employee attitudes and inclinations towards HWI are influenced by a multitude of factors related to will, self-motivation and personality, a variety of organizational and external environmental factors also intervene to a large extent. HWI is an increasingly visible phenomenon, but it has not yet been fully analyzed from the perspective of the factors that determine it, but especially from that of the consequences.

The purpose of this paper is to analyze drivers of HWI in two very different cultures (Romania and Japan), as well as the positive but also negative effects of this investment on their family and organizational relationships. It is also intent to determine whether these relationships are different in Romania and Japan, or they are moderated by the organizational support perceived by the employees and remote working conditions.

The rest of the paper proceeds as follows: In the first chapter, the theoretical framework is presented, including theoretical and empirical arguments that supports the research hypotheses. The second chapter refers to the methodological design, while the third section includes the results obtained through structural equations modelling, including testing of research hypotheses. The last part of the paper includes conclusions, implications and main limits of the research.

\section{Theoretical framework and hypotheses development}

\subsection{Heavy Work Investment}

Due to its potential results for individuals, but also on the level of work performance (WP) and job satisfaction (JS) (Snir and Harpaz, 2012), HWI is a significant phenomenon of modern life. The HWI process is influenced by both social and psychological factors, and it results in certain possible individual and organizational outcomes (Astakhova and Hogue, 2014).

In the literature, there are several perspectives from which the meaning of HWI is viewed. Most commonly, the types of HWI considered are (Shimazu, et al., 2015): work addiction (or workaholism) and work engagement. Other researchers (Snir and Harpaz, 2012) indicated two 
other major types of HWI: (1) situational type (e.g., based on financial need and employeroriented) and (2) dispositional type (e.g., work addiction, devotion, and work engagement).

Research in the field of work addiction is of great interest. Work addiction is associated with an excessive time commitment (Beek, 2009), more precisely with two indicators: overload and time proportion (Schaufeli, Shimazu and Taris, 2009). Work engagement is defined as a positive, work-related mood that is characterized by vigor, passion, dedication, and involvement (Schaufeli, et al., 2002).

Both types of HWI analyzed mainly in the literature, namely work addiction and work engagement, are characterized by large personal investment in their work from the employee side, in terms of time and effort (Shimazu, et al., 2015). Moreover, in different cultures, there may be connections between work addiction and work engagement. For instance, some authors, analyzing the Japanese context, have pointed to that work addiction and work involvement are positively related, but in a week manner (Shimazu and Schaufeli, 2009).

\subsection{Motivation and HWI}

Motivation is a psychological force that generates complex cycles of goal-directed thought and behavior (Shkoler and Zur, 2019). Work motivation is mostly categorized into two types, intrinsic (IM) and extrinsic motivation (EM), showing that different incentives have a distinct impact on employee motivation (Kuranchie-Mensah and Amponsah-Tawiah, 2016).

Over time, various types and motivational forms have been analyzed in the literature regarding their influence on HWI. However, several studies investigated the results and effects of types of IM and EM. In terms of IM, motivation is linked to positive aspects of well-being, such as work engagement and work enjoyment (Richer, Blanchard and Vallerand, 2002). Regarding the EM, even though previous studies have demonstrated the positive connection between this type of motivation and HWI, there are also studies that claim the opposite. For instance, Scafuri Kovalchuk, et al. (2019) argued that when workrelated motivation is externally regulated, employees perceive their actions as being directly controlled by organization, and that can have negative effects on subsequent performance and employee engagement.

Between the two countries which represent the main object of study of this paper (Romania and Japan), there are significant differences regarding the motivational system and how people perceive motivation. Romanian employees are dominantly motivated by salary, job security and incentives (Hauser, 2014) and the most important motivational factors from the Romanian employee point of view are: job authority, responsibility and autonomy, job stability and professional development (Căşuneanu, 2011; Simion-Melinte, Giurgiu and Abrudan, 2015). Nevertheless, it appears that the strongest factors of motivation for Romanian employees are related to financial gain (Achim, Dragolea and Bălan, 2013). By comparation, in the Japanese context, employees may even be dissatisfied when they receive only material rewards, because receiving this kind of rewards implies that they need to work harder to get material rewards again in the future (Zhao and Pan, 2017). According to Liu and Zhao (2006), Japanese organizations are characterized by a high spirit of harmony, and the motivation of Japanese employees must be related to strengthening the sense of team unity and solidarity. Moreover, attitudes such as working hard and doing one's best are strongly promoted and are recognized as values in the Japanese society. 
The employees of Japanese organizations always exhibit high levels of motivation and are oriented toward high achievement and performance (Haghirian, 2010). Hence, considering all above:

H1: EM will be positively associated with HWI - TC.

H2: EM will be positively associated with HWI - WI

H3: IM will be positively associated with HWI - TC.

H4: IM will be positively associated with HWI - WI.

\subsection{Outcomes of HWI}

The outcomes of HWI were divided differently in the literature. The model proposed by Snir and Harpaz (2012), divided the outcomes of HWI as follows: (1) as having positive/mixed/negative nature, (2) in the short/intermediate/long term, and (3) for the individual, for his/her family, and for his/her workplace. According to Houlfort, et al. (2014), depending on the type of passion underlying HWI, individual outcomes can be positive (e.g., harmonious passion leads to JS and WP) or negative (e.g., obsessive passion leads to depression and work-family conflict (WFC). The present study considers four outcomes of HWI, namely overall JS, WP, WFC and turnover intention (TI).

Overall job satisfaction. Overall job satisfaction is a psychological state that is affected not only by organizational factors, but also by the beliefs of the individual employee (Shragay and Tziner, 2011). According to Houlfort, et al. (2014) overall satisfaction is influenced by harmonious passion. There are also studies aimed at investigating the influence of HWI types on JS. For example, the results of the study conducted by Su (2019) have demonstrated that work addiction is negatively related to JS, while employee engagement is positively related to JS. Because JS positively influences organizational commitment (Burlea-Șchiopoiu, 2007; Podsakoff, LePin and LePin, 2007), it can be regarded as a positive outcome of HWI. Therefore:

Hs: HWI - TC will be positively associated with JS.

H6: HWI - WI will be positively associated with JS.

Work performance. Work-related performance represents the highest level of employee results, which requires the allocation of significant resources of time and effort. According to Brown and Leigh (1996), superior performance can be built through greater involvement. The relationship between HWI and performance has been studied by numerous researchers. There is a positive connection between engagement and performance, according to various research results (Shimazu, et al., 2015). However, even if it is difficult to achieve, performance is a positive result of HWI. Therefore, the following hypotheses emerge:

H7: HWI - TC will be positively associated with WP.

Hs: HWI - WI will be positively associated with WP.

Work-family conflict. Work-family balance is essential for both employee well-being and the long-term productive interest of the economy (Lee, McCann and Messenger, 2007). Some authors (Di Stefano and Gaudiino, 2018) have shown that work addiction is positively associated with WFC, in both work-to-family and family-to-work directions, while engagement was negatively associated with both directions of conflict between work and family. By focusing on external and internal factors in relation to work enjoyment, one of the variables chosen by Shkoler, Rabenu and Tziner (2017), was WFC. The results 
indicated a negative relation between WFC and Work Enjoyment. In the end, WFC represents a negative outcome of HWI, which on the other hand may lead to a higher material standard of living (Snir and Harpaz, 2012). Therefore:

H9: HWI - TC will be negatively associated with WFC.

$\mathbf{H}_{\mathbf{1 0}}$ : HWI - WI will be negatively associated with WFC.

Turnover intention. TI is a psychological outcome of excessive job demand and too few job supplies. It is also a negative psychological state in which the employee focuses on avoiding negative consequences rather than facing positive ones (Ahmed and Khan, 2015). Over time, TIs are expected to translate into the certainty of turnover (Richer, Blanchard and Vallerand, 2002) and they are, therefore, considered to be negative outcomes of HWI. By demonstrating that job autonomy and social support are negatively associated with TIs, Kim and Stoner (2008) stated that TI should be viewed as an HWI outcome of experiencing different job conditions. According to Houlfort, et al. (2014), workers who frequently experience depressive symptoms should have higher levels of TIs. Therefore:

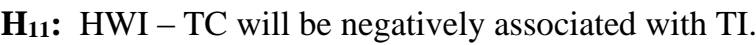

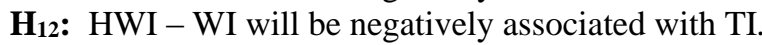

Moreover, considering all above, we assume that:

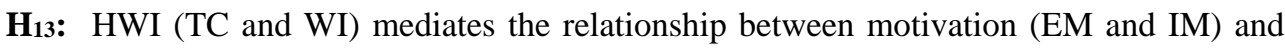
HWI outcomes (JS, WP, WFC and TI).

\subsection{Cultural perspective on HWI}

Different perceptions of HWI arise from specific characteristics of history, economy, and the development perspectives of each nation, but also from common conceptions and shared understandings of the meaning and importance of work. The cultural differences impact the way heavy work investors perceive and evaluate their experiences (Di Stefano and Gaudiino, 2019). Recently, Shkoler and Kimura (2020) found that various cultural perceptions can moderate the relationship between motivation and HWI outcomes (e.g., TC and WI). According to Snir and Harpaz (2006), both national culture and the characteristics of the employment sector provide the most common explanations for national-level differences in terms of individual work values, attitudes and behavior toward HWI.

The findings of different research suggest that the attitude of employees towards investing in time or effort differs from one country to another, depending on certain characteristics that underlie cultural uniqueness. According to Snir and Harpaz (2009), time investment in work is heavier in societies where are important survival values compared with those fostering self-expression values. Shkoler, Rabenu and Tziner (2017), emphasized that investments of both time and energy manifest themselves completely different in diverse cultures, particularly between West and East, highlighting that in a western cultural context the work is seen by employees as a place for enjoyment and self-fulfillment, which is different from the eastern cultural context. However, there are also similarities between countries with diametrically opposed cultures, but which have the same perceptions of HWI. For example, Snir and Harpaz (2006) found that there are similarities between Japan and America in terms of HWI, because both countries share the same level of orientation towards time commitment. 
Several investigations have proved that are cross-cultural differences concerning HWI. Conducting an analysis on 20 countries, including Japan, Snir and Harpaz (2012) have found that work investment is heavier in societies where survival values are important. Another study, conducted by $\mathrm{Hu}$, et al. (2014) which analyzed the differences between employees from Western Europe (e.g., Netherlands, Finland and Spain) and from Eastern Asia (e.g., China and Japan) in terms of engagement and work addiction level, reveals that levels of engagement were higher in Western countries than in Eastern countries, while the levels of work addiction were higher in Eastern countries than in Western countries (even though Japanese had the lowest levels of work addiction). Therefore:

H14: The above relationships will be different for Romania and Japan.

\subsection{HWI and organizational support}

OS is not just about recognizing merits through material rewards. It can influence HWI, both in terms of time and effort, especially through the degree of stability of the psychological and moral support included in the motivational system. According to Brown and Leigh (1996) an environment that is perceived as psychologically safe, stable and meaningful by employees, is related to greater commitment of time and energy in the work of the organization.

Research has shown a strong importance of OS in transforming HWI into positive results (i.e., job satisfaction and performance) (Beek, 2009). According to some authors (Converso, et al., 2019), job resources, as physical, psychosocial or organizational dimensions of work (e.g., job security, career opportunities, work climate and task significance), are provided by OS, and can be extremely motivating (both intrinsically and extrinsically) and lead to engagement and indirectly sustain both WP and JS. Similarly, Brown and Leigh (1996) have stated that perceptions related to a motivating and inclusive psychological climate are related directly to job involvement and indirectly to effort (i.e., TC and WI) and performance.

Several studies have explored the influence of some types of HWI on the negative results of this type of investment. A significant positive association was observed between work addiction and TI (Beek, 2009) and between engagement and TI (Beek, et al., 2014). Some studies (Shimazu and Schaufeli, 2009) demonstrated that work addiction is positively associated with ill-health (e.g., psychological distress) and TI, and negatively associated with job and life satisfaction (led by WFC) and performance, while engagement is negatively associated with TI and ill-health, and positively associated with job and life satisfaction and WP. Even if some studies (Wayne, Shore and Liden, 1997) showed that perceived OS was negative in relation to negative outcomes of HWI, the degree to which the organization cares about employee well-being and values their contributions (Eisenberger, et al., 1986), attenuates to some extent the negative influence of HWI on WFC and TIs. Therefore, the following hypotheses emerge:

$\mathrm{H}_{15}$ : The above relationships will be different for the employees receiving low or high OS. 


\subsection{HWI in social distancing conditions}

Many organizations explored remote work opportunities for their employees, but few implemented such initiatives prior to COVID-19. Following the recent spread of COVID-19 and being forced to consider remote work and alternative employment opportunities, corporates have rapidly shifted to utilizing a combination of digital technologies in order to provide existing and incoming employees platforms for collaboration, co-creation and engagement away from the built environment of their physical offices. As a result, the number of internal meetings and the amount of overtime have decreased, while engagement and the willingness to learn and adapt to working with modern technology has increased. The number of organizations utilizing collaborative technology, digital workers, Robotic Process Automation (RPA), Artificial Intelligence (AI), Deep Learning and Blockchain along with human talent is on a rapid increase, as a result of teleworking.

$\mathrm{H}_{16}$ : The above relationships will be different depending whether the work had to be adapted to social distancing conditions.

\section{Methods}

This paper focuses on the positive and negative consequences of HWI, but also on the reasons that lead employees to invest heavily in work, aiming to investigating whether two very different cultures (which are reflected in different attitudes towards work) could impact any significant difference on those relationships. In view of the purpose of the research, it is addressed from a deductive perspective, which involved the development of hypotheses based on theoretical approaches and the results of other relevant studies and the use of appropriate research strategies and methods to test them (Saunders, Lewis and Thornhill, 2009).

An online questionnaire-based survey was organized between March and May 2020. The questionnaire was distributed to Romanian and Japanese employees by a non-probability sampling method, mainly due to the social distancing measures required by the SARS COV2 pandemic conditions. In less than three months, 915 complete responses were received, from which 105 were excluded since the respondents were not able to provide relevant information for the purpose of this study, due the fact that they had to temporarily interrupt their professional activity, as a result of the pandemic conditions. Thus, the total sample of the study was 822, including 639 Romanian employees $(77.74 \%)$ and 183 from Japan $(22.26 \%)$, having between 1 - 49 years of experience in their organizations $(M=9.3$, $\mathrm{SD}=9.562)$. From the total sample, 381 respondents $(46.35 \%)$ declared that they carry out their professional activity normally, while for the rest of $441(53.65 \%)$ the professional activity had been adapted to the current conditions (for instance, by working from home).

To measure the respondents' perception on HWI dimensions (TC and WI) and the considered antecedents (EM and IM) and outcomes (JS, WP, WFC and TC), the questionnaire included several scales adapted from previous studies. Table no. 1 presents the nine scales, the corresponding references and Cronbach Alpha coefficients calculated for this study. 
Table no. 1. Research scales

\begin{tabular}{|c|c|c|c|}
\hline Scale (Symbol) & Items & References & $\begin{array}{c}\text { Cronbach } \\
\text { Alpha }\end{array}$ \\
\hline Extrinsic motivation (EM) & 7 & \multirow{2}{*}{$\begin{array}{l}\text { Burduș and Popa, 2016; Ștefan and Popa, } \\
\text { 2018; Ștefan, Popa and Albu, } 2020\end{array}$} & 0.899 \\
\hline Intrinsic motivation (IM) & 8 & & 0.933 \\
\hline Time commitment (HWI - TC) & 5 & \multirow{2}{*}{ Brown and Leigh, 1996; Tziner, et al., 2019} & 0.905 \\
\hline Work intensity (HWI - WI) & 5 & & 0.940 \\
\hline Job satisfaction (JS) & 4 & $\begin{array}{l}\text { Eisenberger, et al., 1997; Quinn and Shepard, } \\
\text { 1974; Snir and Harpaz, } 2012\end{array}$ & 0.959 \\
\hline Work performance (WP) & 1 & WHO, 2002; Shimazu and Schaufeli, 2009 & - \\
\hline Work-family conflict (WFC) & 3 & $\begin{array}{c}\text { Geurts, et al., 2005; Bakker, et al., 2009; Snir } \\
\text { and Harpaz, } 2012\end{array}$ & 0.947 \\
\hline Turnover intention (TI) & 4 & van Beek, 2014; van Beek, et al., 2014 & 0.927 \\
\hline Organizational support (OS) & 8 & $\begin{array}{c}\text { Eisenberger, et al., 1986; Eisenberger, et al., } \\
1997\end{array}$ & - \\
\hline
\end{tabular}

Source: authors after mentioned references

The questionnaire also included some demographic questions to describe the sample structure (area of activity, hierarchical position within the organization, work experience, etc.) and the grouping of respondents for multigroup analysis (MGA) (type of work and perception of OS).

SPSS Statistical package, version 26 (IBM Corp., 2019) was employed for preliminary data preparation and descriptive statistics, while for specification and evaluation of measurement and structural model, testing research hypotheses and multigroup analysis (MGA), partial least square structural equation modeling (PLS-SEM) with SmartPLS 3.3.2 (Ringle, et al., 2015) was considered. The research hypotheses were examined through the bootstrap procedure with 3000 re-samplings, without sign modification, allowing the direct and indirect effects, associated t-statistics and corrected confidence intervals (BIC) to be computed. PLS-SEM was selected due to the ability to simultaneously specify and estimate all structural relationships needed for testing the research hypotheses.

\section{Results and discussions}

The PLS-SEM model has been specified to include eight latent reflexive constructs corresponding to the two dimensions of the HWI, its antecedents and consequences, as well as the structural relations between them to enable the testing of research hypotheses.

To evaluate the measurement model, as recommended by (Hair, et al., 2017), (1) internal consistency, by means of Cronbach's Alpha coefficient $(\alpha)$ and composite reliability ( $\left.\rho \_A\right)$, (2) convergent validity, respectively indicators' factor loadings and average variance extracted (AVE) and (3) discriminant validity, respectively heterotrait-monotrait ratio (HTMT) and cross-loading were considered. The results of the measurement model evaluation showed values higher than those recommended, respectively (Henseler, Ringle and Sarstedt, 2015; Hair, et al., 2017): indicator loadings $>0.70, \alpha>0.70 ; \rho_{A}>0.70$; AVE $>0.50$ and the HTMT ratio $<0.90$, supporting the validity and fidelity of the measurement model.

Further, the structural model assessment considered a holistic approach, in terms of $\mathrm{R}^{2}$, effect size $\left(\mathrm{f}^{2}\right)$ and significance and relevance of path coefficients. (Chin, 1998; Hair, et al., 2017). The full model is presented in figure no. 1. 


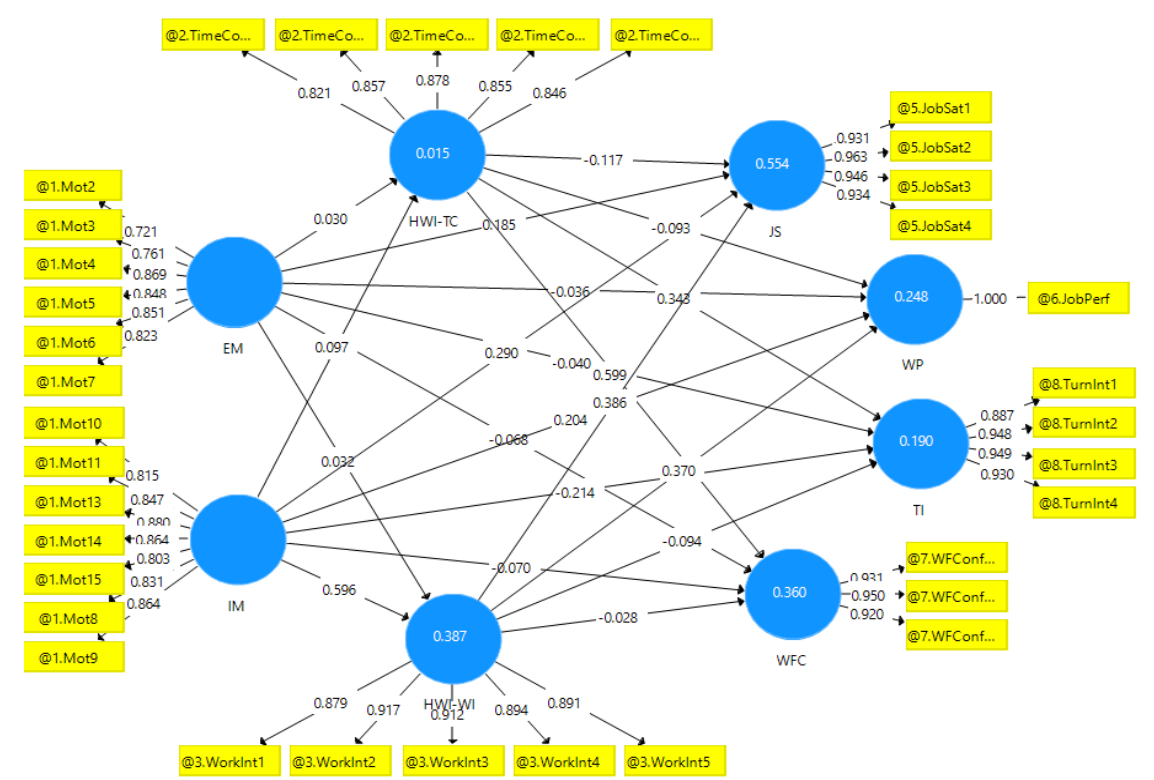

Figure no. 1. The full structural model

Source: authors with SmartPLS 3.3.2 (Ringle, et al., 2015)

The predictive value of the structural model was first evaluated in terms of $R$ squared coefficients $\left(R^{2}\right)$. Thus, EM and IM explain (together) $38.7 \%$ of the variance in HWI-WI $\left(\mathrm{R}^{2}=0.387\right)$ and only $1.5 \%$ in HWI-TC $\left(\mathrm{R}^{2}=0.015\right)$, suggesting that the HWI-TC is mainly determined by predictors other than motivation. Moreover, the two sides of motivation together with HWI explain more than half of JS $\left(\mathrm{R}^{2}=0.554\right)$, while (at the opposite side), only $19.0 \%$ of TI $\left(\mathrm{R}^{2}=0.190\right)$. It should be noticed that the predictive power of the model is higher for positive and personal outcomes of HWI.

Direct Effects Analysis $\left(\mathrm{H}_{1}-\mathrm{H}_{12}\right)$. To validate the first 12 hypotheses, the direct effects between HWI and its predictors and results are presented in table no. 2. Also, there are included the decisions on the acceptance of each hypothesis and the effect size $\left(\mathrm{f}^{2}\right)$.

Table no. 2. Direct effects of the full model (hypotheses H1 - H12)

\begin{tabular}{ccccccc}
\hline Hypothesis & Relationship & $\boldsymbol{\beta}$ & SE & $\boldsymbol{t}$ & Decision & $\mathbf{f}^{2}$ \\
\hline H1 & EM - > HWI-TC & 0.030 & 0.059 & 0.500 & Not supported & 0.000 \\
H2 & EM - HWI-WI & 0.032 & 0.048 & 0.668 & Not supported & 0.001 \\
\hline H3 & IM -> HWI-TC & $0.097^{*}$ & 0.056 & 1.736 & Supported & 0.004 \\
H4 & IM -> HWI-WI & $0.596^{* * *}$ & 0.047 & 12.711 & Supported & $0.230^{* * *}$ \\
\hline H5 & HWI-TC - JS & $-0.117^{* * *}$ & 0.024 & 4.928 & Supported & $0.030^{*}$ \\
H6 & HWI-WI -> JS & $0.386^{* * *}$ & 0.038 & 10.113 & Supported & $0.204 * * *$ \\
\hline H7 & HWI-TC -> WP & $-0.093^{* *}$ & 0.032 & 2.927 & Supported & 0.011 \\
H8 & HWI-WI -> WP & $0.370^{* * *}$ & 0.046 & 7.986 & Supported & $0.112^{* * *}$ \\
\hline H9 & HWI-TC -> WFC & $0.599^{* * *}$ & 0.025 & 23.971 & Supported & $0.553^{* * *}$ \\
H10 & HWI-WI - W WFC & -0.028 & 0.037 & 0.759 & Not supported & 0.001 \\
\hline H11 & HWI-TC -> TI & $0.343^{* * *}$ & 0.032 & 10.888 & Supported & $0.143^{* * *}$ \\
H12 & HWI-WI -> TI & $-0.094^{*}$ & 0.043 & 2.203 & Supported & 0.007 \\
\hline
\end{tabular}

Notes: $* p<0.05, * * * p<0.001, \beta=$ standardized path coefficients, $\mathrm{SE}=$ standard errors, $\mathrm{F}^{2}=$ effect size. 
As concerns the impact of motivation on HWI, the empirical results found no support for the effect of EM on HWI ( $\beta=0.030$, ns; $\beta=0.032$, ns), while IM proves to have a positive one both on HWI-TC $(\beta=0.097, \mathrm{p}<0.05)$ and HWI-WI $(\beta=0.596, \mathrm{p}<0.001)$. Moreover, the effect size $\left(\mathrm{f}^{2}\right)$ of the IM on HWI-WI (i.e. the change in the $\mathrm{R}^{2}$ of the HWI-WI, in case that IM is excluded from the model) could be considered as a moderate one $\left(f^{2}=0.230, p<\right.$ 0.001) (Cohen, 1988; Hair, et al., 2017). The above results suggest that only the IM could determine the Romanian and Japanese employees to increase their investment in work, both in terms of time commitment and work intensity.

Considering the impact of HWI on the positive outcomes, the significant and negative path coefficients suggest a negative impact of HWI-TC on JS $(\beta=-0.117, p<0.001)$ and WP $(\beta$ $=-0.093, \mathrm{p}<0.01)$, while HWI-WI has positive impact $(\beta=0.386, \mathrm{p}<0.001 ; \beta=0.370$, $\mathrm{p}$ $<0.001)$. It should also be noted that the significant moderate effect size of HWI-WI on JS $\left(\mathrm{f}^{2}=0.204, \mathrm{p}<0.001\right)$. On other words, the Romanian and Japanese employees' investment in work in terms of work intensity, will be positively reflected on their job satisfaction (JS) and work-related performance (WP). However, the time commitment, as investment in work, will determine job dissatisfaction and low work performance.

Finally, we assumed that HWI will also be associated with negative outcomes, respectively, WFC and TI. The positive and significant path coefficients support the positive effect of HWI-TC on WFC and TI $(\beta=0.599, \mathrm{p}<0.001 ; \beta=0.343, \mathrm{p}<0.001)$, while HWI-WI has negative significant impact on TI $(\beta=0.599, \mathrm{p}<0.001)$. It also may be noticed that there is a strong effect size of HWI-TC on WFC $\left(\mathrm{f}^{2}=0.553, \mathrm{p}<0.001\right)$. The results presented above suggest that, the investment in work as time commitment will be reflected in more intense work-family conflict and turnover intention. However, the work intensity will have opposite effects, determining the employees to work further in the same organization.

Mediation analysis (Hypothesis $\mathrm{H}_{13}$ ). Besides the direct relationships of HWI with its antecedents and outcomes, we also assumed that HWI (TC and WI) mediates the relationship between motivation (EM and IM) and HWI outcomes (JS, WP, WFC and TI). Table no. 3 presents the direct and specific indirect effects (both for HWI-TC and HWI-WI as mediators) and their associated bias corrected confidence intervals obtained through the bootstrapping procedure (Nitzl, et al., 2016).

Table no. 3. Direct and indirect effects of the full model (hypotheses H13)

\begin{tabular}{|c|c|c|c|c|c|c|c|}
\hline \multirow{3}{*}{ Relationships } & \multirow{3}{*}{$\begin{array}{l}\text { Direct } \\
\text { effects }\end{array}$} & \multicolumn{6}{|c|}{ Indirect effects } \\
\hline & & \multicolumn{3}{|c|}{ MV: HWI-TC } & \multicolumn{3}{|c|}{ MV: HWI-WI } \\
\hline & & $\boldsymbol{\beta}$ & 95 & BCI & $\boldsymbol{\beta}$ & 95 & 3CI \\
\hline EM -> JS & $0.185 * * *$ & -0.003 & -0.018 & 0.010 & 0.012 & -0.025 & 0.047 \\
\hline IM -> JS & $0.290 * * *$ & -0.011 & -0.028 & 0.000 & $0.230 * * *$ & 0.173 & 0.295 \\
\hline EM -> WP & -0.036 & -0.003 & -0.016 & 0.008 & 0.012 & -0.024 & 0.048 \\
\hline IM -> WP & $0.204 * * *$ & -0.009 & -0.027 & 0.000 & $0.221 * * *$ & 0.163 & 0.292 \\
\hline EM -> WFC & -0.068 & 0.018 & -0.053 & 0.087 & -0.001 & -0.010 & 0.002 \\
\hline IM -> WFC & -0.070 & 0.058 & -0.006 & 0.126 & -0.017 & -0.062 & 0.025 \\
\hline EM -> TI & -0.040 & 0.010 & -0.030 & 0.052 & -0.003 & -0.016 & 0.005 \\
\hline IM -> TI & $-0.214 * * *$ & 0.033 & -0.002 & 0.074 & $-0.056 *$ & -0.109 & -0.008 \\
\hline
\end{tabular}

Notes: $* p<0.05, * * p<0.01, * * * p<0.00, \mathrm{MV}=$ mediator variable,

$\beta=$ standardized path coefficients, $95 \mathrm{BCI}=$ bias corrected confidence intervals. 
Given the positive direct effects of IM on JS and WP $(\beta=0.290, p<0.001 ; \beta=0.204$, $\mathrm{p}<0.001)$ and also the positive specific indirect effects trough HWI-WI $(\beta=0.230,95 \mathrm{BCI}$ $[0.173,0.295] ; \beta=0.221,95 \%$ BCI $[0.163,0.292])$, we may conclude that HWI-WI mediates the relationships between IM the positive outcomes of HWI, such as the positive effects of IM on employees' JS and WP will be stronger if they invest in work intensity. On the other hand, the negative direct effect of IM on TI $(\beta=-0.214, p<0.001 ; \beta=0.204)$ and the negative specific indirect effects trough HWI-WI $(\beta=-0.056,95$ BCI [- 0.109, - 0.008]), support the mediation of HWI-WI on the IM - TI relationship. Hence, investing in work intensity will further decrease the chances of intrinsically motivated employees to leave the organization. It should also be noted that HWI-TC does not mediate any of the relationships between motivation dimensions and HWI outcomes. Therefore, the empirical results only partially supported hypothesis H13.

Multigroup analysis (hypotheses $\mathrm{H}_{14}-\mathrm{H}_{16}$ ). In addition to investigating what factors could determine someone to heavily invest time and effort in work and what kind of consequences the investment could generate for employees, their family and organizations, we were also interested to determine whether this relationships were affected by some unique intra or extra organizational conditions: (1) national culture, reflected in work culture; (2) work adaptation to social distancing conditions imposed by the SARS COV2 pandemic crisis, and (3) organizational support as perceived by employees. Therefore, the multigroup analysis (PLS-MGA) (Henseler, et al., 2009) was employed to determine the significance of the path coefficients across predetermined groups built on above mentioned criteria. The PLS-MGA results are presented in figure no. 2.

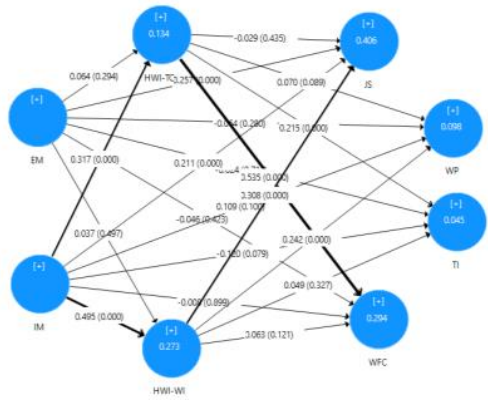

a. Group A - Romania ( $=639)$

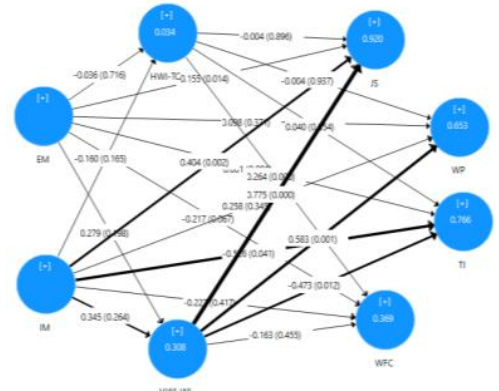

b. Group B - Japan $(\mathbf{N}=183)$

Note: Significant path coefficients differences (group A - group B): all paths
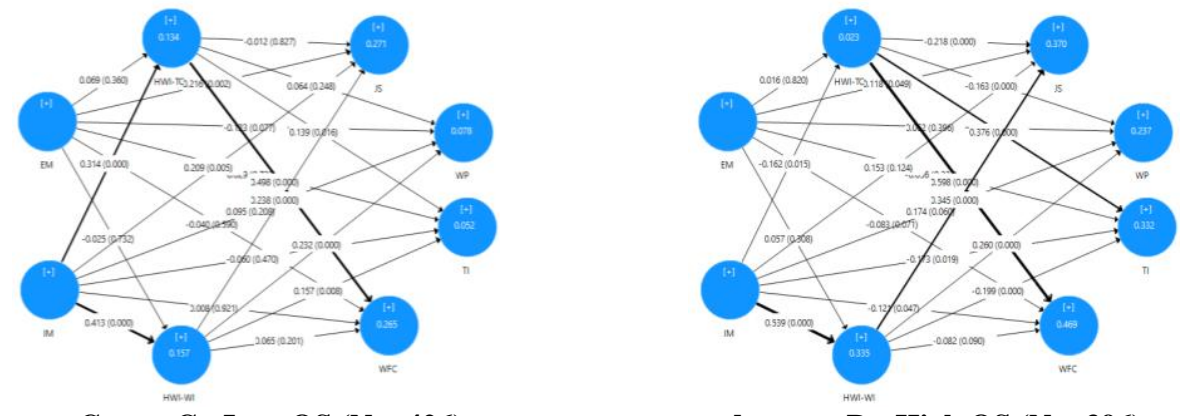

d. group D - High OS $(\mathrm{N}=396)$

Note: Significant path coefficients differences (Group C - Group D): IM -> HWI-TC; HWI-TC -> JS; HWI-TC -> WP; HWI-TC -> TI; HWI-WI -> WFC; HWI-WI -> TI. 


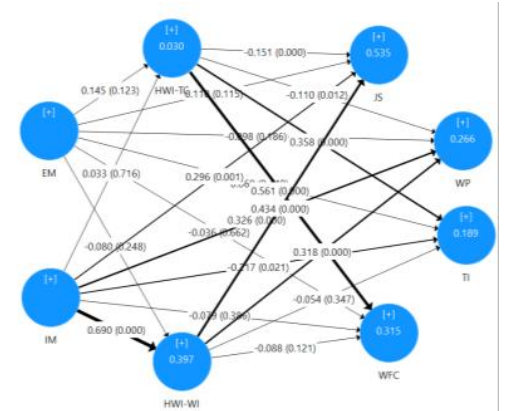

e. Group E - Working normally $(\mathrm{N}=381)$

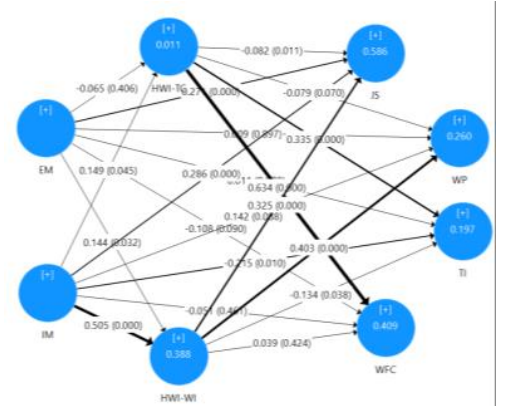

f. group $F$ - Remote working $(N=441)$ Note: Significant path coefficients differences (group E - group F): EM -> HWI-WI; IM -> HWI-WI

Figure no. 2. MGA results (validation of hypothesis $M_{14}-H_{16}$ )

As one may see in figure no. $2 \mathrm{a}$ and $2 \mathrm{~b}$, the PLS-MGA indicates that all the path coefficients are different for the Romanian and Japanese groups, suggesting that the national culture, reflected on the employee attitude towards work has a significant impact on the motives that determine who they heavily invest time and effort in their work and also on the consequences of that investment. Moreover, the perceived organizational support may determine differences mainly in the outcomes of HWI, by diminishing the negative effects of WI, but also the positive effects of TC (see figure no. 2c and 2d). As concerns the distance work conditions, a decrease in the effects of IM and an increase in the effects of EM on WI (figure no. 2e and 2f) can be observed.

Although IM and EM are positively associated with HWI (Shkoler and Kimura, 2020), in specific contexts, only one type of motivation could persuade employees to increase their HWI (as in the present case). Having strong psychological and social implications, HWI often positively influences JS and WP, and negatively influences TC and WFC. Moreover, employees form beliefs in relation to perceived OS (Hutchison and Sowa, 1986), and they also expect support by their organizations (Gündüz, 2014), because in this way, they can invest in the skills that they need to improve HWI outcomes. Therefore, the impact of HWI dimensions on HWI outcomes will be different, depending on the perceived OS.

\section{Conclusions}

This paper focuses on the positive and negative consequences of HWI, aiming to investigate if two very different national cultures could impact any significant difference on those relationships. The total sample of the study was 822, including 639 Romanian employees and 183 employees from Japan. The research hypotheses proposed were validated trough partial least square structural equation modeling (PLS-SEM).

Research results suggest that only the IM could determine the Romanian and Japanese employees to increase their investment in work. As regards the positive or negative effect of the two dimensions of HWI (TC and WI) on HWI outcomes, the research results suggest that investing in work through a sustained effort (WI) has beneficial effects both personally and professionally. Furthermore, by analyzing the mediation effect of HWI, it was found that WI mediates the relationship between IM and the positive outcomes of HWI. On the other hand, a massive investment of time dedicated to work fosters the emergence of professional dissatisfaction, decreased performance and imbalances between work and 
family life. Finally, OS could lead to differences in HWI outcomes, while remote working decreases the effects of IM and increases EM's effects on WI.

The research results have strong methodological implications, as the present paper concretely analyzes the influences and effects of HWI, in the comparative context of Romania-Japan. From a practical point of view, results can be useful both for employees who are not fully aware of the effects of HWI, but also for organizations, who may be interested in the most effective ways to motivate employees to invest time and effort in their work, to balance these investments so as to maximize their beneficial outcomes and diminish unwanted ones, but also to the fact that HWI results can be influenced by OS and remote working.

The research took place during the period when both Romania and Japan were facing the COFID-19 pandemic, which provided the opportunity to study the analyzed phenomena in the context of remote work. To date, there is very little research that has addressed this issue, which gives the paper a strong novelty character, as well as immediate applicability in managerial practice. On the other hand, this context has also led to some research limits, mostly associated with online surveys (such as the non-probability sampling method) with consequences also for the sample structure.

Therefore, future research could determine whether the analyzed relationships in this paper will be similar under "normal" conditions. Moreover, future research could also consider the influence of other types of motivation on HWI, but also the influence of other factors (besides motivation). Also, since research frequently addresses work addiction, as a dimension of HWI, future empirical research could also consider the impact of work addiction on HWI outcomes.

\section{References}

Achim, I.M., Dragolea, L. and Bălan, G., 2013. The Importance of Employee Motivation to Increase Organizational Performance. Annales Universitatis Apulensis Series Oeconomica, 15(2), pp.685-691.

Ahmed, I. and Khan, M., 2015. Predicting Work Motivation Through Job Satisfaction and Turnover Intentions: The Explanatory Role of Heavy Work Investment. The Lahore Journal of Busines, 4(1), pp.75-89.

Astakhova, M. and Hogue, M., 2014. A heavy work investment typology: a biopshychosocial framework. Journal of Managerial Psychology, 29(1), pp.81-99.

Brown, S. and Leigh, T., 1996. A New Look at Psychological Climate and Its Relationship to Job Involvement. Journal of Applied Psychology, 81(4), pp.358-368.

Burduș, E. and Popa, I., 2016. Reproiectarea managementului organizației. București: Pro Universitaria.

Burlea-Șchiopoiu, A., 2007. An Approach of the Knowledge Management for the Development of the Organisational Commitment. In: W. Wojtkowski, W.G. Wojtkowski, J. Zupancic, G. Magyar and G. Knapp eds., 2007. Advances in Information Systems Development. Boston: Springer, pp.313-323.

Cășuneanu, C., 2011. The Romanian employee motivation system: an empirical analysis. International Journal of Mathematical Model and Methods in Applied Sciences, 5(5), pp.931-937.

Chin, W.W., 1998. The partial least squares approach for structural equation modeling. In: G.A. Marcoulides ed., 1998. Methodology for business and management. Modern methods for business research. Mahwah, NJ: Lawrence Erlbaum Associates, pp.295-336. 
Cohen, J., 1988. Statistical power analysis for the behavioral sciences. 2nd ed. NY: Lawrence Erlbaum Associates.

Converso, D., Sottimano, I., Molinengo, G. and Loera, B., 2019. The Unbearable Lightness of the Academic Work: The Positive and Negative Sides of Heavy Work Investment in a Sample of Italian University Professors and Researchers. Sustainability, 11(8), p.2439.

Di Stefano, G. and Gaudiino, M., 2018. Differential Effects of Workaholism and Work Engagement on the Interference Between Life and Work Domains. Europe's Journal of Psychology, 14(4), pp.863-879.

Di Stefano, G. and Gaudiino, M., 2019. Workaholism and work engagement: how are they similar? How are they different? A systematic review and meta-analysis. European Journal of Work and Organizational Psychology, 28(3), pp.329-347.

Eisenberger, R., Huntington, R., Hutchison, S. and Sowa, D., 1986. Perceived organizational support. Journal of Applied Psychology, 71(3), pp.500-507.

Eisenberger, R., Cummings, J., Armeli, S. and Lynch, P., 1997. Perceived Organizational Support, Discretionary Treatment, and Job Satisfaction. Journal of Applied Psychology, 82(5), pp.812-820.

Geurts, S.A., Taris, T.W., Kompier, M.A., Dikkers, J.S., Van Hooff, M.L. and Kinnunen, U.M., 2005. Work-home interaction from a work pscychologial perspective: Development and validation of a new questionnaire. the SWING. Work \& Stress, 19(4), pp.319-339.

Haghirian, P., 2010. Understanding Japanese Management Practices. New York: Business Expert Press.

Hair, J.F., Hult, G.T., Ringle, C. M. and Sarstedt, M., 2017. A primer on partial least squares structural equation modeling (PLS-SEM). 2nd ed. Thousand Oaks: SAGE.

Hauser, L., 2014. Workplace motivation in Romania: what are the main factors and their cultural background?. In: s.n, The 8th International Management Conference. Bucharest, Romania, 6-7 November 2014. Bucharest: s.n.

Henseler, J., Ringle, C.M. and Sinkovics, R.R., 2009. The Use of Partial Least Squares Path Modeling in International Marketing. In: R. SinKovics and P.N. Ghauri eds., 2009. Advances in International Marketing. Bingley: Emerald, pp.277-320.

Henseler, J., Ringle, C.M. and Sarstedt, M., 2015. A new criterion for assessing discriminant validity in variance-based structural equation modeling. Journal of the Academy of Marketing Science, 43(1), pp.115-135.

Houlfort, N., Philippe, F., Vallerand, R. and Ménard, J., 2014. On passion and heavy work investment: personal and organizational outcomes. Journal of Managerial Psychology, 29(1), pp.25-45.

Hu, Q., Schaufeli, W.B., Taris, T.W., Hessen, D.J., Hakanen, J.J., Salanova, M. and Shimazu, A., 2014. "East is East and West is Est and Never the Twain Shall Meet:" Work Engagement and Workaholism Across Eastern and Western Cultures. Journal of Behavioral and Social Sciences, 1(1), pp.6-24.

IBM Corp., 2019. IBM SPSS Statistics for Windows, Version 26.0. Armonk (NY): IBM Corp.

Kim, H. and Stoner, M., 2008. Burnout and Turnover Intention Among Social Workers: Effects of Role Stress, Job Autonomy and Social Support. Administration in Social Work, 32(3), pp.5-25. 
Kuranchie-Mensah, E.B. and Amponsah-Tawiah, K., 2016. Employee Motivation and Work Performance: A Comparative Study of Mining Companies in Ghana. Journal of Industrial Engineering and Management, [e-journal] 9(2), pp.255-309, doi:10.3926/jiem.1530.

Lee, S., McCann, D. and Messenger, J.C., 2007. Working Time Around the World. Trends in working hours, laws and policies in a global comparative perspective. Geneva: International Labour Office.

Liu, L.W. and Zhao, E.D., 2006. Comparasion and Analysis of Employee Motivation in Cross-Culture Project Management. In: s.n., International Symposium on Advancement of Construction Management and Real Estate. Beijing, China, 3-5 November 2006. S.l:s.n.

Malinowska, D., Tokarz, A. and Wardzichowska, A., 2018. Job autonomy in relation to work engagement and workaholism: mediation of autonomus and controlled work motivation. International Journal of Occupational Medicine and Environmental Health, [e-journal] 31(4), pp.445-458. doi:10.13075/ijomeh.1896.01197.

Podsakoff, N.P., LePin, J.A. and LePin, M.A, 2007. Differential Challenge Stressor Hindrance Stressor Relationships with Job Attitudes, Turnover Intentions, Turnover, and Withdrawal Behavior: A Meta-Analysis. Journal of Applied Psychology, [e-journal] 92(2), pp.438-454. doi:10.1037/0021-9010.92.2.438.

Quinn, R.P. and Shepard, L.J., 1974. The 1972-73 Quality of Employment Survey. Descriptive Statistics, with Comparison Data from the 1969-70 Survey of Working Conditions. Ann Arbor, Michigan: Michigan University, Inst. for Social Research.

Richer, S., Blanchard, C. and Vallerand, R., 2002. A motivational model of work turnover. Journal of Applied Social Psychology, 32(10), pp.2089-2113.

Ringle, C.M., Wende, S. and Becker, J.M., 2015. SmartPLS 3.3.2. Bönningstedt: SmartPLS $\mathrm{GmbH}$.

Saunders, M., Lewis, P. and Thornhill, A., 2009. Research Methods for Business Students. 5th ed. Harlow: Pearson Education.

Scafuri Kovalchuk, L., Buono, C., Ingusci, E., Maiorano, F., De Carlo, E., Madaro, A. and Spagnoli, P., 2019. Can Work Engagement Be a Resource for Reducing Workaholism's Undesirable Outcomes? A Multiple Mediating Model Including Moderated Mediation Analysis. International Journal of Environmental Research and Public Health, [ejournal] 16(8), p.1402. doi:10.3390/ijerph16081402.

Schaufeli, W., 2016. Heavy work investment, personality and organizational climate. Journal of Managerial Psychology, 31(6), pp.1057-1073.

Schaufeli, W.B., Salanova, M., González-Romá, V. and Bakker, A.B., 2002. The Measurement of Engagement and Burnout: A Two Sample Confirmatory Factor Analytic Approach. Journal of Happiness Studies, 3, pp.71-92.

Schaufeli, W., Shimazu, A. and Taris, T., 2009. Being Driven to Work Exessively Hard. The Evaluation of a Two-Factor Measure of Workaholism in The Netherlands and Japan. Cross-Cultural Research, [e-journal] 43(4), pp.320-348. doi:10.1177/ 1069397109337239.

Shimazu, A. and Schaufeli, W., 2009. Is Workaholism Good or Bad for Employee Wellbeing? The Distinctiveness of Workaholism and Work Engagement among Japanese Employees. Induatrial Health, 47(5), pp.495-502. 
Shimazu, A., Schaufeli, W., Kamiyama, K. and Kawakami, N., 2015. Workaholism vs. Work Engagement: The Two Different Predictors of Future Well-being and Performance. International Journal Behavioural Medicine, 22(1), pp.18-23.

Shkoler, O. and Kimura, T., 2020. How Does Work Motivation Impact Employees' Investment at Work and Their Job Engagement? A Moderated-Moderation Perspective Through an International Lens. Frontiers in Psychology, 11, p.38.

Shkoler, O., Rabenu, E. and Tziner, A., 2017. The dimensionality of workaholism and its relations with internal and external factors. Journal of Work and Organizational Psychology, [e-journal] 33(3), pp.193-203. doi:10.1016/j.rpto.2017.09.002.

Shragay, D. and Tziner, A., 2011. The Generational Effect on the Relationship between Job Involvement, Work Satisfaction, and Organizational Citizenship Behavior. Revista de Psicología del Trabajo y de las Organizaciones, 27(2), pp.143-157.

Simion-Melinte, C., Giurgiu, A. and Abrudan, M.M., 2015. Facitating the transition of students from school to work through interactive methods such as simulated enterprise in the construction and production of construction materials. In: s.n., The $9^{\text {th }}$ international Management Conference. Bucharest, Romania, n.d. s.l:s.n.

Snir, R. and Harpaz, I., 2006. The workaholism phenomenon: A cross-national perspective. Career Development International, 11(5), pp.374-393.

Snir, R. and Harpaz, I., 2009. Cross-Cultural Differences Concerning Heavy Work Investment. Cross-Cultural Research, 43(4), pp.309-319.

Snir, R. and Harpaz, I., 2012. Beyond workaholism: Towards a general model of heavy work investment. Human Resource Management Review, 22(3), pp.232-243.

Ștefan, S.C. and Popa, Ș.C., 2018. Health workers motivation and quality of care. A Path Analysis approach. In: s.n., The 31st IBIMA Conference - Innovation Management and Education Excellence through Vision 2020. Millan, Italy, 25-26 April 2018. S.1: s.n.

Ştefan, S.C., Popa, Ş.C. and Albu, C.F., 2020. Implications of Maslow's Hierarchy of Needs Theory on Healthcare Employees' Performance. Transylvanian Review of Administrative Sciences, [e-journal] 16(59), pp.124-143. doi:10.24193/tras.59E.7.

Su, J., 2019. Working Hard and Work Outcomes: The Relationship of Workaholism and Work Engagement with Job Satisfaction, Burnout, and Work Hours. Dissertation. Illinios State University.

Tziner, A., Shkoler, O. and Zur, B., 2019. Revisiting Work Engagement from a ModeratedMediation Vantage Point. Journal of Work and Organizational Psychology, [e-journal] 35(3), pp.207-215. doi:10.5093/jwop2019a22.

van Beek, I., 2014. Understanding the dark and bright sides of heavy work investment: Psychological studies on workaholism and work engagement. PhD thesis. Utrecht University.

van Beek, I., Taris, T., Schaufeli, W. and Brenninkmeijer, V., 2014. Heavy work investment: its motivational make-up and outcomes. Journal of Managerial Psychology, [e-journal] 29(1), pp.46-62, doi:10.1108/JMP-06-2013-0166.

WHO, 2002. World Health Organization Health and Performance Questionnaire (HPQ): Clinical Trials Baseline Version. Geneva: World Health Organization.

Zhao, B. and Pan, Y., 2017. Cross-Cultural Employee Motivation in International Companies. Journal of Human Resource and Sustainability Studies, 5(7), pp.215-222. 